Short Communication

Human and Medical Genetics

\title{
Non-mosaic partial duplication $12 p$ in a patient with dysmorphic characteristics and developmental delay
}

Jakeline Santos Oliveira $^{1}$ (D), Tatiana Mozer Joaquim ${ }^{2}$, Rosana Aparecida Bicudo da Silva ${ }^{1}$, Deise Helena de Souza $^{1}$, Lúcia Regina Martelli $^{2}$ and Danilo Moretti-Ferreira ${ }^{1}$

${ }^{1}$ Universidade Estadual Paulista "Júlio de Mesquita Filho" (UNESP), Instituto de Biociências, Departamento de Ciências Químicas e Biológicas, Botucatu, SP, Brazil.

${ }^{2}$ Universidade de São Paulo, Faculdade de Medicina de Ribeirão Preto, Departamento de Genética, Ribeirão Preto, SP, Brazil.

\begin{abstract}
Duplication of the short arm of chromosome 12 is a rare chromosomal abnormality that may arise de novo or result from malsegregation of a balanced parental translocation. This study comprises the clinical description, cytogenetic and cytogenomic analyses and genotype-phenotype correlation in a patient with facial dysmorphism, developmental delay and intellectual impairment caused by non-mosaic partial duplication and a paracentric inversion 12p. The patient's GTG-banded karyotype was 46,XX,invdup(12)(pter $\rightarrow$ p13.32::p11.1 $\rightarrow$ p13.31::p13.31 $\rightarrow$ qter). A genetic gain of approximately $28 \mathrm{Mb}$ was detected in the chromosomal region arr[GRCh37]12p13.31p11.1(6914072_34756209)x3. The chromosomal alteration seen in our patient is described as "pure" partial duplication 12p. In most cases, duplication 12p phenotype is characterized by dysmorphic features, multiple congenital anomalies and intellectual disability. A small number of cases in literature have described genes associated with neurodevelopmental disease, such as ING4, CHD4, MFAP5, GRIN2B, SOX5, SCN8A and PIANP. In our patient the duplication $12 p$ was de novo. This study should contribute to the genotype-phenotype correlation in partial duplication $12 \mathrm{p}$ cases.
\end{abstract}

Keywords: Duplication 12p, array-CGH, facial dysmorphism.

Received: September 27, 2018; Accepted: March 05, 2019.

Duplication of the short arm of chromosome 12, first described by Uchida and Lin (1973), is a rare chromosomal abnormality with an estimated incidence of 1/50,000 live births (Stengel-Rutkowski et al., 1981). According to (Allen et al., 1996) cases of duplication 12p can be divided into five categories based on the extent of the region duplicated and whether other chromosomal aneusomies are present. Category I is designated as a partial "pure" trisomy of $12 p$ with a duplication point distal to $12 \mathrm{p} 11$ and not involving any other chromosome. Category II includes cases with trisomies 12p in association with cell-line mosaicism. Category III includes cases with complete and "pure" $12 p$ trisomy with an additional trisomy or monosomy of the short arm of an acrocentric chromosome. Category IV and V involves complete trisomy $12 p$ with monosomy or trisomy of non-acrocentric chromosomes other than $12 p$, or trisomic involvement of $12 q$, respectively. The duplication of $12 p$ is

Send correspondence to: Danilo Moretti-Ferreira. Universidade Estadual Paulista "Júlio de Mesquita Filho" (UNESP), Instituto de Biociências, Departamento de Ciências Químicas e Biológicas, Campus de Botucatu, Rua: Rubião Junior S/N, 18.618-000 Botucatu, SP, Brazil. E-mail: danilo.moretti@unesp.br. defined as "complete" when there is duplication region of $12 \mathrm{p} 11$ or $12 \mathrm{p} 12-12 \mathrm{pter}$. The duplication of $12 \mathrm{p}$ is considered "pure" as having no other aneusomy or additional aneusomies of only the pter regions of non-acrocentric chromosomes, and not involving mosaicism (Allen et al., 1996).

By these criteria, (Liang et al., 2006) compared 23 patients with "pure" trisomy 12p, subdividing the cases into four subgroups (A, B, C and D) to refine the karyotypephenotype correlation based on the extent of $12 \mathrm{p}-\mathrm{du}-$ plicated region involved. Subgroup A is complete $12 p$ trisomy, subgroup is B terminal trisomy $12 p$, subgroup is C distal trisomy $12 p$ and subgroup is D proximal trisomy $12 p$.

Approximately 50 cases of duplications $12 p$ have been described in the medical literature to date consisting of small studies and case reports, that are limited to descriptions of the clinical syndrome at birth or in early infancy. Little is known about the life expectancy of these children, beyond infancy and most of the diagnostic criteria are based on descriptions of infants and adolescents (Segel et al., 2006; Inage et al., 2010; Liu et al., 2012; Poirsier et al., 2014; Mekkawy et al., 2016). The clinical signs most com- 
monly associated with duplication $12 \mathrm{p}$ are increased weight at birth, hypotonia, craniofacial anomalies such as turricephaly, macrocephaly, round face, full cheeks, frontal bossing, wide nasal bridge, short nose, anteverted nares, long philtrum, thin upper lip, short neck, dysmorphic ears, intellectual impairment and moderate to severe psychomotor delay (Hung et al., 2012; Poirsier et al., 2014).

Some dysmorphic features such as sparse hair and eyebrows, hypertelorism, wide and depressed nasal bridge, short nose with wide and anteverted nares, up-slanting palpebral fissures, epicanthic folds, full cheeks, long philtrum, and short neck seen in patients with $12 \mathrm{p}$ duplication overlap with patients with Pallister-Killian syndrome (PKS) (OMIM: 601803) (Inage et al., 2010). The PKS is typically caused by the presence of a supernumerary isochromosome composed of the short arms of chromosome 12 , generating tetrasomy $12 \mathrm{p}$, which is often present in a tissue limited mosaic state (Peltomäki et al., 1987). However, some characteristics such as pigmentary skin differences, diaphragmatic hernia, congenital heart defects, and other systemic abnormalities are present only in patients with PKS (Izumi et al., 2012).

In most of the reported cases, duplication $12 \mathrm{p}$ resulted from malsegregation of a balanced parental translocation (Segel et al., 2006). Duplication 12p may also arise de novo from misalignment of low copy repeats (LCRs) through non-allelic homologous recombination (NAHR) (De Gregori et al., 2005).

The present study included the clinical description, cytogenetic and cytogenomic analyses, as well as genotype-phenotype correlation in a patient with facial dysmorphism, developmental delay and intellectual impairment caused by non-mosaic partial duplication $12 \mathrm{p}$, de novo.
This 15-year-old girl, the only child of young and healthy non-consanguineous parents, was born at 40 weeks after uneventful pregnancy and delivery. Her birth weight

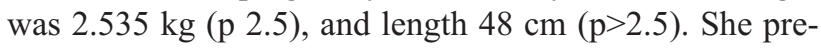
sented jaundice at birth, and, therefore, received phototherapy for five days. At one year, the patient showed having seizures with recurrence. In the first genetics clinical evaluation, at 2,1 yo, height $86 \mathrm{~cm}(\mathrm{p}<3.95)$, weight $12.5 \mathrm{~kg}$ $(\mathrm{p}<3.58)$ and OCP $47.5 \mathrm{~cm}$ (percentile $<2)$. Showed a broad forehead, flat face, narrow eye slits, microblepharon, anteverted nostrils, low nasal root with a broad nasal base, smooth nasolabial philtrum, tent-shaped upper lip, (Figure 1) scoliosis, single simian crease in the left hand, bilateral flat foot, right genu valgum, developmental delay and intellectual disability. In the follow up at 13 yo, information was that she could walk and talk when she was 3 yo. At 6 yo, she underwent surgical correction of genu valgum and showed short lower limbs. She developed thelarche at 10 yo, and pubarche at 11 yo. At that time, her cholesterol was 600 $\mathrm{mg} / \mathrm{dL}$, and she had hypothyroidism, good comprehension but unable to read or write.

Chromosomal analysis was carried out on temporary peripheral lymphocyte cultures obtained from the patient and her parents as described by Moorhead and Furman (1960), with modifications. GTG banding (550 bands) was performed as described by Seabright (1971) and high-resolution banding according to Yunis (1976), both with modifications. The patient's GTG-banded karyotype was 46,XX,invdup(12)(pter $\rightarrow \quad$ p13.32::p11.1 $\rightarrow$ p13.31::p13.31 $\rightarrow$ qter) while the karyotype of both parents were normal. FISH analysis, performed according to the instructions of the manufacturer, using a WCP chromosome 12 probe (Cytocell Aquarius ${ }^{\mathrm{TM}}$ Oxford Gene Technology),

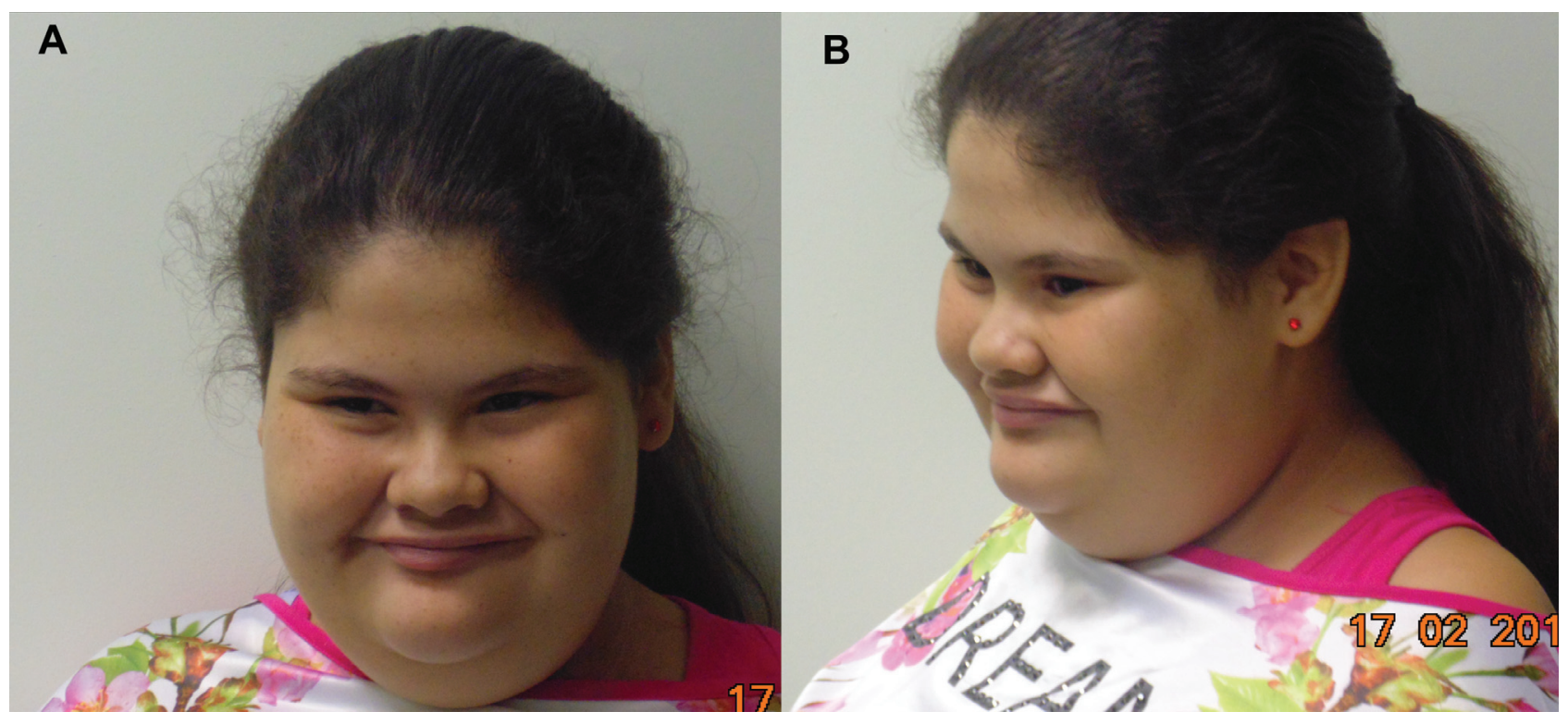

Figure 1 - Patient at 13 years. (A) Frontal view. (B) Side view. Note the frontal humps, flat cheeks, round face, full cheeks, short nose, low nasal bridge, thin upper lip and short neck. 
revealed that one of the homologous chromosomes differed in size (Figure 2).

For cytogenomic analysis, DNA was extracted from $200 \mu \mathrm{L}$ of the patient's whole blood using the MasterPure Complete DNA and RNA Purification Kit (Epicentre, US) according to the manufacturer's instructions. Array-CGH was performed using the GenetiSure ${ }^{\mathrm{TM}} \mathrm{CGH}+\mathrm{SNP}$ $4 \times 180 \mathrm{k}$ platform (Agilent). The data were analyzed using Nexus Copy Number software (Biodiscovery v. 8.0). Our analyses were based on the reference genome GRCh37/hg19 and online databases such as UCSC Ge- nome Browser (GRCh37/hg19), Database of Genomic Variants (DGV), Database of Chromosomal Imbalance and Phenotype in Humans Using Ensembl Resources (DECIPHER), Online Mendelian Inheritance in Man (OMIM) and PubMed. The array-CGH analysis showed a large genetic gain of approximately $27.842,138$ base pairs $\left(\begin{array}{lll}\sim & 28 & \mathrm{Mb}\end{array}\right) \quad \operatorname{arr}[\mathrm{GRCh} 37] 12 \mathrm{p} 13.31-\mathrm{p} 11.1$ (6914072_34756209)x3, including 282 genes (Figure 3).

The first patient with a duplication $12 p$ was clinically diagnosed initially as having Down syndrome, due to the similarity of flat face and clinical features such as epi-
A

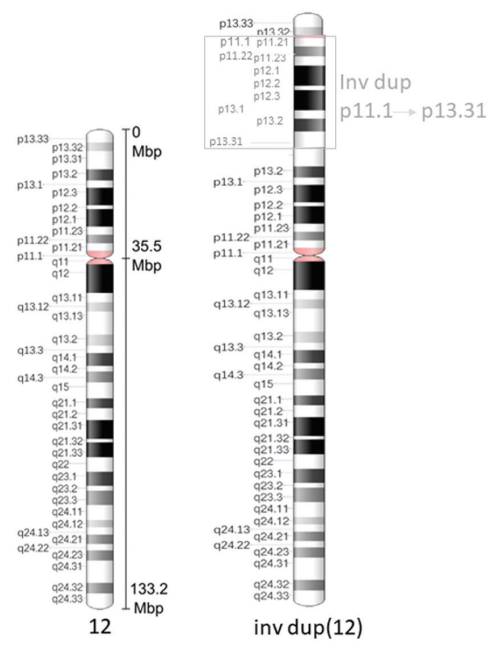

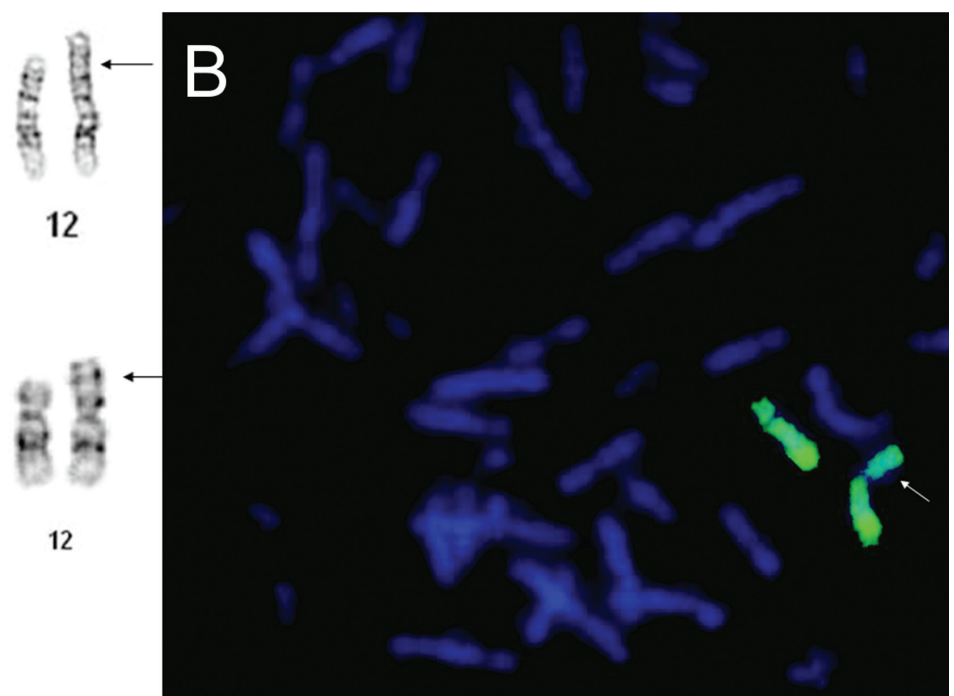

Figure 2 - Chromosome 12 karyotyping and FISH. (A) GTG-banded karyotype of patient showing the normal and duplication and inversion paracentric 12p. (B) FISH metaphase using WCP probe for chromosome 12 of CYTOCELL AQUARIUS ${ }^{\circledR}$ Oxford Gene Technology indicating a difference in size in one of the patient's homologous chromosome, the arrow indicates the duplication $12 \mathrm{p}$.
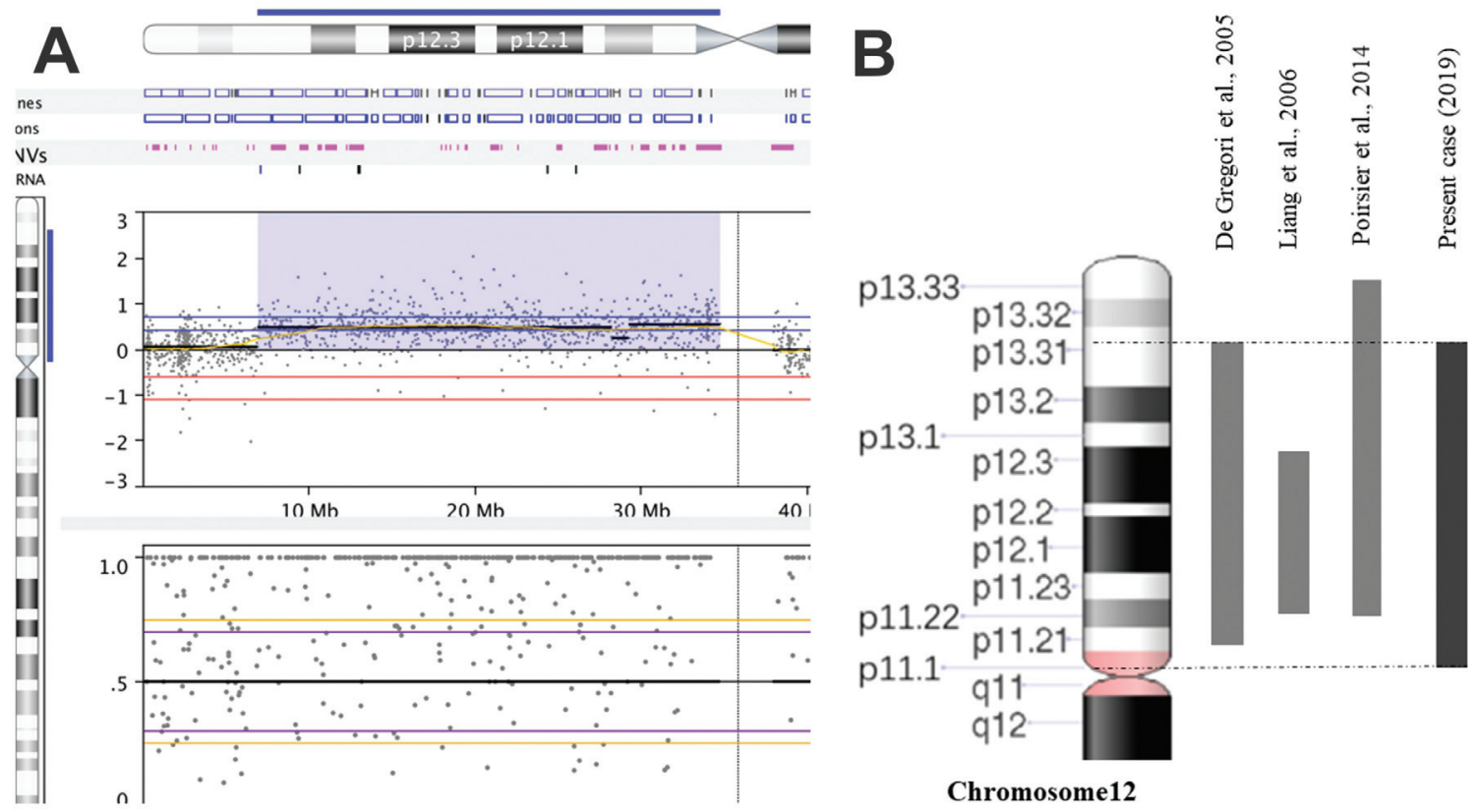

Chromosome12

Figure 3 - Chromosome 12 characterization. (A) Array-CGH of chromosome 12, the color blue indicates the duplicated chromosomal region 12p13.31 $\rightarrow$ p11.1 of $\sim 28 \mathrm{Mb}$ in size. (B) Duplication 12p patients reported in the literature with chromosome region similar to that of the present case. 
canthus, broad nasal bridge, bilateral simian creases, abnormal dermal patterns and intellectual disability. However, chromosomal analysis by quinacrine dihydrochloride was revealed a trisomy $12 \mathrm{p}$ and monosomy of the distal region of chromosome 8 (Uchida and Lin, 1973).

Since then, several researchers aimed at correlating the karyotype-genotype-phenotype with duplication $12 \mathrm{p}$ (Inage et al., 2010). However, duplication $12 \mathrm{p}$ is a chromosomal alteration with little recurrence of cases in the literature. In addition, there is a great phenotypic variability due to the different sizes and chromosome breaks of the $12 \mathrm{p}$ duplication (Eid et al., 2014).

De Gregori et al. (2005) describe the characterization of an interstitial duplication of 12p, dup (12) (p11.21 $\rightarrow$ p13.31), by array-CGH and FISH in a patient with mental retardation and dysmorphic features. They hypothesized that the duplication $12 p$ could have been generated by homology of three blocks of low copy repeats (LCRs) flanking the duplication region. They suggested that misalignment of these LCRs could have mediated the recurrent rearrangement type de novo.

The duplicated chromosomal region in our patient is similar to that described by De Gregori et al. (2005), and in keeping with the LCRs model, the origin of the duplication in our patient is de novo. However, in our patient the orientation of the duplicated chromosomal segment is inverted.

The karyotype-phenotype correlation in our patient allows us to characterize the extent of the duplicate chromosome fragment into Category I and, depending on the extent of duplication, in the subgroup of group D (Allen et al., 1996; Liang et al., 2006). Category I is said to be the most benign group in trisomy $12 \mathrm{p}$, in addition to points of $12 \mathrm{p}$ distal to $12 \mathrm{p} 11$ (Allen et al., 1996).

Among the subgroups of "pure" partial trisomy, the clinical features, such as broad ears and deformities in the feet were mapped to a segment of $5 \mathrm{Mb}$, the 12p13.1-p12.3 segment, because they were present in subgroup A and $\mathrm{C}$ patients, but not in subgroups B and D patients (Allen et al., 1996; Rauch et al., 1996; Zumkeller et al., 2004; Liang et al., 2006). In our patient these clinical features are not present.

Epicanthal folds, ear anomalies, short neck, and round face/prominent cheeks were observed in groups A, $\mathrm{B}$, and $\mathrm{C}$ patients, but not in group $\mathrm{D}$ patients, suggesting that these features may be associated with a segment telomeric to 12p12.3 (Tekin et al., 2001; Tsai et al., 2005; Liang et al., 2006). However in our patient, round face/prominent cheeks and short neck were described, in addition to the 12 p12 region duplication. The common phenotype is in most cases independent of the category, being facial dysmorphism, and developmental delay (Allen et al., 1996; Rauch et al., 1996).

Compared with cases described in the literature with "pure" partial duplication 12p similar to the duplication region of our patient, the clinical description included a round face, full checks, proeminent forehead/frontal, short nose, wide/depressed nasal bridge, anteverted nostril, long/deep philtrum, large downward facing mouth, and inverted lower lip (Table 1) are present in most cases of Category I and subgroup D (De Gregori et al., 2005; Liang et al., 2006; Poirsier et al., 2014).

The clinical findings, such as hypotonia, high forehead, prominent cheeks, flat face, large philtrum, short nose with anteverted nostril, broad everted lower lip, and short neck are in agreement with the partial duplication $12 p$ in our patient. Although our patient did not present increased birth weight, she is currently overweight (Rauch et al., 1996).

The duplicated $12 \mathrm{p} 13.1$ region present in patients previously described in the literature contributes to the hypothesis that this region contains genes that are sensitive to gene dosage and that this region could be responsible for facial dysmorphism (Rauch et al., 1996; Tsai et al., 2005). This region is also altered in cases of PKS with overlapping facial features for 12p duplication/PKS (Izumi et al., 2012). The diagnosis of PKS requires the identification of mosaic isochromosome $12 \mathrm{p}$ by conventional karyotyping and FISH (Hung et al., 2012). Our patient showed clinical features consistent with a duplication $12 \mathrm{p}$, but since no isochromosome $12 \mathrm{p}$ was detected by karyotyping and FISH, the patient was diagnosed with non-mosaic partial duplication $12 p$.

Izumi et al. (2012) hypothesized that duplication of the genes located within 12p13.31 might be sufficient to result in the core phenotype of $12 \mathrm{p}$ duplication/PKS. According to these authors, ING4, CHD4 and MFAP5, represent strong candidate genes, given their important roles in cell proliferation and differentiation. Moreover, alterations in these genes have been associated with neurological disorders.

According to Segel et al. (2006), genes that are important for early morphogenesis are affected by trisomy, while genes that are important for fetal and placental growth are not. However, genes responsible for brain development (functional and possibly structural) continue to be affected throughout pregnancy, resulting in poor brain development, and trisomy $12 \mathrm{p}$ influences the early developmental milestones, as well as cognitive and neurological function. Patients with trisomy $12 \mathrm{p}$ chromosome tend to have seizures at seven or eight years of age. In our patient, the seizures began in the first years of life, becoming recurrent. She also has speech and motor delay, and intellectual disability.

Currently, the use of array-CGH, is aimed at the elucidation of genetic variants, such as Copy Number Variants (CNVs) that can overlap genes and consequently alter the phenotype. The study of (Coe et al., 2014) correlated CNVs associated with many neurocognitive disorders in individuals with developmental delay. Among the mapped gain/duplication type CNVs, these overlap the GRIN2B, SOX5, 
Table 1 - Comparison of the clinical features of patients with "pure" duplication 12p subgroup D.

\begin{tabular}{|c|c|c|c|c|}
\hline Clinical features & $\begin{array}{l}\text { De Gregori et al., } 2005 \\
\text { p11.21 } \rightarrow \text { p13.31 }\end{array}$ & $\begin{array}{c}\text { Liang et al., } 2006 \\
\text { inv } \operatorname{dup}(12) \mathrm{p} 12.3 \rightarrow \mathrm{p} 11.22\end{array}$ & $\begin{array}{c}\text { Poirsier et al., } 2014 \\
\text { Patient } 1 \\
\text { p13.33 } \rightarrow \text { p } 11.21\end{array}$ & $\begin{array}{c}\text { Present case } \\
\text { inv dup(12) p13.31 } \rightarrow \text { p11.1 }\end{array}$ \\
\hline Round face & + & - & + & + \\
\hline Full cheeks & NR & + & + & + \\
\hline Prominent forehead/Frontal & + & + & + & + \\
\hline Hypertelorism & NR & NR & + & - \\
\hline Epicanthus & NR & - & + & - \\
\hline Occipital plane & NR & NR & NR & - \\
\hline Short nose & + & + & + & + \\
\hline Wide/Depressed nasal bridge & + & + & + & + \\
\hline Anteverted nostril & + & + & + & + \\
\hline Long/deep philtrum & + & - & + & + \\
\hline Micrognathia & NR & NR & + & + \\
\hline Big mouth facing down & + & + & + & + \\
\hline Thin upper lip & NR & NR & + & + \\
\hline Inverted lower lip & + & + & + & + \\
\hline Low-Eyed ears & + & + & + & - \\
\hline Dysmorphic ears & NR & + & + & - \\
\hline Short neck & NR & - & + & + \\
\hline Hypotonia & NR & - & + & + \\
\hline Seizure & NR & NR & - & + \\
\hline Developmental delay & + & + & + & + \\
\hline
\end{tabular}

+, feature present; -, negative feature; nr, not reported/not determined.

SCN8A and PIANP genes in the 12p12.1 and 12p13.3 regions. These genes act in the central nervous system and craniofacial development and are potential candidates for neurological changes in patients with $12 \mathrm{p}$ duplication (Poirsier et al., 2014).

Most reports of cases of duplication $12 p$ describe the clinical characteristics of the patients and conventional cytogenetics analysis. Only for six cases of duplication $12 \mathrm{p}$, an array-CGH analysis was performed to refine the chromosomal break points and describe the genes inserted in the duplicated chromosomal region, thus improving the genotype-phenotype correlation (De Gregori et al., 2005; Hung et al., 2012; Izumi et al., 2012; Liu et al., 2012; Poirsier et al., 2014; Mekkawy et al., 2016).

In conclusion, we describe a case of a rare chromosomal imbalance leading to partial duplication $12 \mathrm{p}$ and inversion of de novo origin that could have been generated as a result of the misalignment of LCR blocks. The phenotype-karyotype correlation showed similarities to previously reported cases of partial duplications $12 p$. Few cases in literature have described genes associated with neurodevelopmental disease, such as ING4, CHD4, MFAP5, GRIN2B, SOX5, SCN8A and PIANP. Our results contribute to the hypothesis that the $12 \mathrm{p} 13.3$ region is responsible for most of the dysmorphic features of duplication $12 \mathrm{p}$.

\section{Acknowledgments}

We thank the patient and her parents for their cooperation and the IBB-Unesp Graduate Program in Biological Sciences (Genetics). This study was financed in part by the Coordenação de Aperfeiçoamento de Pessoal de Nível Superior- Brazil (CAPES) - Finance Code 001. The authors thank Dr. Jeremy Squire for critically reviewing the English in the revised version of this manuscript.

\section{Conflict of interest}

The authors declare that there is no conflict of interest that could be perceived as prejudicial to the impartiality of the reported research.

\section{Author contributions}

JSO generated and analyzed the data, visualization and writing of original draft, TMJ generated and analyzed the data and wrote the manuscript, RABS generated and DHS conceved the study, generated the data and participated in the writing, LRM provided resources and partici- 
pated in the writing, reviewing and editing of the manuscript, DMF project administrated and supervised the project, participated in the writing, reviewing and editing of the manuscript. All authors read and approved the final version.

\section{References}

Allen TL, Brothman AR, Carey JC and Chance PF (1996) Cytogenetic and molecular analysis in trisomy 12p. Am J Med Genet 63:250-256.

Coe BP, Witherspoon K, Rosenfeld JA, van Bon BWM, Vultovan Silfhout AT, Bosco P, Friend KL, Baker C, Buono S, Vissers LELM et al. (2014) Refining analyses of copy number variation identifies specific genes associated with developmental delay. Nat Genet 46:1063-1071.

De Gregori M, Pramparo T, Memo L, Gimelli G, Messa J, Rocchi M, Patricelli MG, Ciccone R, Giorda R and Zuffardi O (2005) Direct duplication 12p11.21-p13.31 mediated by segmental duplications: A new recurrent rearrangement? Hum Genet 118:207-213.

Eid MM, Helal SI, Meguid NA, Hamad SA, Gerzawy A and Kamel A (2014) Nonmosaic partial duplication 12p: clinical and cytogenetic findings and review of the literature $12 p$ duplication clinical and cytogenetic description. Med Res J 13:68-73.

Hung CC, Lin CH, Lin SY, Shin JC, Lee CN and Su YN (2012) Prenatal diagnosis of a fetus with a de novo trisomy $12 \mathrm{p}$ by array-comparative genomic hybridization (array-CGH). Gene 495:178-182.

Inage E, Suzuki M, Minowa K, Akimoto N, Hisata K, Shoji H, Okumura A, Shimojima K, Shimizu T and Yamamoto T (2010) Phenotypic overlapping of trisomy $12 p$ and Pallister-Killian syndrome. Eur J Med Genet 53:159-161.

Izumi K, Conlin LK, Berrodin D, Fincher C, Wilkens A, Haldeman-Englert C, Saitta SC, Zackai EH, Spinner NB and Krantz ID (2012) Duplication 12p and Pallister-Killian syndrome: A case report and review of the literature toward defining a Pallister-Killian syndrome minimal critical region. Am J Med Genet Part A 158 A:3033-3045.

Liang D, Wu L, Pan Q, Harada N, Long Z, Xia K, Yoshiura KI, Dai H, Niikawa N, Cai F et al. (2006) A father and son with mental retardation, a characteristic face, inv(12), and insertion trisomy 12p12.3-p11.2. Am J Med Genet A 140:238244.

Liu YH, Xie RG, Zhang XY, Wei SD, He Y, Xu WF, Lin YY and Xiong F (2012) A new partial trisomy $12 p$ with artery catheter vagus, congenital cataracts, external auditory canal, and no turbinate. Gene 509:164-167.

Mekkawy MK, Mazen IM, Kamel AK, Vater I and Zaki MS (2016) Genotype/phenotype correlation in a female patient with $21 \mathrm{q} 22.3$ and 12p13.33 duplications. Am J Med Genet Part A 170:1050-1058.

Moorhead ED and Furman NH (1960) A chronopotentiometric study of gallium. Anal Chem 32:1507-1509.
Peltomäki P, Knuutila S, Ritvanen A, Kaitila I and Chapelle AD LA (1987) Pallister-Killian syndrome: cytogenetic and molecular studies. Clin Genet 31:399-405.

Poirsier C, Landais E, Bednarek N, Nobecourt JM, Khoury M, Schmidt P, Morville P, Gruson N, Clomes S, Michel N et al. (2014) Report on 3 patients with 12p duplication including GRIN2B. Eur J Med Genet 57:185-194.

Rauch A, Trautmann U and Pfeiffer RA (1996) Clinical and molecular cytogenetic observations in three cases of "trisomy 12p syndrome". Am J Med Genet 63:243-249.

Seabright M (1971) A rapid banding technique for human chromosomes. Lancet 298:971-972.

Segel R, Peter I, Demmer LA, Cowan JM, Hoffman JD and Bianchi DW (2006) The natural history of trisomy 12p. Am J Med Genet A 140:695-703.

Stengel-Rutkowski S, Murken JD, Frankenberger R, Riechert M, Spiess H, Rodewald A and Stene J (1981) New chromosomal dysmorphic syndromes. 4. Trisomy 12p. Eur J Pediatr 136:249-262.

Tekin D, Wüsthof A, Harms E and Meinecke P (2001) De novo inverted tandem duplication of the short arm of chromosome 12 in a patient with microblepharon. Am J Med Genet A 104:42-46.

Tsai ACH, DiGiovanni M, Walton C and Cotter PD (2005) De novo duplication of the short arm of chromosome 12: dup(12)(p13.1p13.3). Am J Med Genet A 134:229-230.

Uchida IA and Lin CC (1973) Identification of partial 12 trisomy by quinacrine fluorescence. J Pediatr 82:269-272.

Yunis JJ (1976) High resolution of human chromosomes. Science 191:1268-1270.

Zumkeller W, Volleth M, Muschke P, Tönnies H, Heller A, Liehr T, Wieacker P and Stumm M (2004) Genotype/phenotype analysis in a patient with pure and complete trisomy $12 \mathrm{p}$. Am J Med Genet A 129:261-264.

\section{Internet Resources}

Nexus software, http://www.biodiscovery.com/nexuscopy-number/ (accessed 18 November 2017).

UCSC genome Browser, https://genome.ucsc.edu/ (accessed 04 June 2018).

Database of Genomic Variants (DGV), http://dgv.tcag.ca/dgv/app/home (accessed 06 June 2018).

Database of Chromosomal Imbalance and Phenotype in Humans Using Ensembl Resources (DECIPHER), https://decipher.sanger.ac.uk/ (accessed 05 July 2018).

Online Mendelian Inheritance in Man (OMIM), http://omim.org/ (accessed 23 July 2018).

US National Library of Medicine National Institutes of Health (PubMed), https://www.ncbi.nlm.nih.gov/pubmed/ (accessed 01 August 2018).

Associate Editor: Maria Angélica Cortez

License information: This is an open-access article distributed under the terms of the Creative Commons Attribution License (type CC-BY), which permits unrestricted use, distribution and reproduction in any medium, provided the original article is properly cited. 